\title{
CORES DA CIDADE APREENDIDAS SOB A LUZ NATURAL - MÉTODOS E ENSAIOS EM BUSCA DA REPRESENTACÃO GRÁFICA
}

CITY COLORS UNDER NATURAL LIGHT - METHODS AND TESTS IN SEARCH OF GRAPHICAL REPRESENTATION

\section{PORTO, MARIA MAIA}

D. Sc.,Professora UFRJ, mariamaiaporto@ufri.br

\section{ALVAREZ, ADRIANA}

M.Sc, Professora UFRJ,alvarezz@uol.com.br

\section{RAMOS, TIAGO}

Arquiteto e Urbanista, pesquisador AMBEE/UFR, tiago.qmr@gmail.com

\section{BRAGA, DIEGO}

Arquiteto e Urbanista, pesquisador AMBEE/UFRJ, diegodomingosbraga@gmail.com

\section{LIMA, GABRIELLY}

Graduando em Arquitetura e Urbanismo, Iniciação científica AMBEE/UFRJ, gabriellylima77@gmail.com

\section{ANTUNES, ISABELA}

Graduando em Arquitetura e Urbanismo, Iniciação científica AMBEE/UFRJ, isabela.terencio@gmail.com

\section{MORAES, DANIEL}

Graduando em Arquitetura e Urbanismo, Iniciação científica AMBEE/UFRJ, danielmoraes.ara@gmail.com

\section{RESUMO}

O artigo parte de pesquisa para elaboração de metodologia que auxilie na identificação e representação gráfica de imagens urbanas sob luz natural. Tem como objetivo mostrar métodos e ensaios elaborados no Centro da Cidade do Rio de Janeiro, destacando limites inerentes à complexidade da atividade e a importância da percepção visual como balizadora dos julgamentos ao longo do processo. Instrumentos acessíveis ao estudante de arquitetura e ao arquiteto e urbanista, empregados regularmente no levantamento de informações sobre o contexto ambiental urbano, visando o projeto, foram utilizados. O roteiro metodológico dos ensaios seguiu os seguintes passos: I. visitas à área de estudo com registros preliminares; II. identificação de variações da iluminação natural no que diz respeito à trajetória solar e condições de nebulosidade; III. levantamento de aspectos históricos e culturais do lugar; IV. elaboração de dados primários - fotografias e desenhos, in loco; V. elaboração de dados secundários e representativos - paletas de cores. VI. análise dos resultados. No artigo são discriminados os grupos de elementos considerados representativos na apreensão visual do lugar estudado - edificações, mercadorias e pessoas; os fundamentos e métodos associados à suas representações gráficas; resultados parciais de alguns ensaios e destaques relativos a recursos e instrumentos.

PALAVRAS-CHAVE: cor na cidade; percepção visual da cor sob luz natural; cores do Saara - RJ.

\section{ABSTRACT}

The article is based on research for elaboration of graphical representation methodology of urban images under natural light. It aims to show methods and results obtained from a study in the center of the city of Rio de Janeiro, some limits inherent to the complexity of the activity and the importance of visual perception throughout the process. Common tools to architecture students and architects urbanists were used. The methodological outline of the tests followed the steps: I. visits to the study area to preliminary records; II. identification of natural light variations both with respect to the sun path as cloudy conditions; III. survey of historical and cultural aspects; IV. preparation of primary data - photographs and drawings, in loco; V. development of secondary and representative data-color palettes. VI. analysis of the results. Groups of representative elements of the visual apprehension of the area were discriminated: buildings, goods and people in the streets. Fundamentals and methods associated with their graphical representations were shown. Finally some steps and instruments were briefly discussed. 
A cor, vista nas ruas da cidade, conta com a luz natural para que seja revelada. A identificação de seus atributos é feita através da percepção humana, numa interação de cunho subjetivo. A paisagem, e suas dinâmicas, composta pela interação de elementos de presença duradoura ou provisória, tem aparência variável sob a luz do sol e do céu: imagens que devem ser representadas graficamente, mesmo que parcialmente, por meio de métodos que agreguem objetividade ao processo de análise do contexto urbano, como prática em Arquitetura.

A complexidade inerente à apreensão da paisagem e de determinada ambiência não deveria inibir sua representação gráfica. Importante, sobretudo, quando se reconhece o valor da dimensão cultural envolvida. Nesse sentido, há contribuições de trabalhos que são referências para iniciativas que partem da apreensão da imagem visualizada para compor registros gráficos da paisagem, com aplicação de métodos adaptados a objetivos e contextos específicos.

Ações relativas ao mapeamento das cores existentes numa localidade tiveram no Atelier 3D Couleur de Jean Phillipe LENCLOS uma forte referência e a instituição de uma disciplina e de um profissional chamado colorista. (PORTER, MIKELLIDES, 2009). Para Lenclos, as cores contribuem para a afirmação de uma identidade nacional, regional ou local na medida em que estão associadas, entre outros fatores, à geografia, geologia e luz, além de cultura. Seu método tem sido composto por três processos: análise, síntese e apresentação de um vocabulário para cada localidade. A análise busca identificar as características predominantes e detalhe cromático de uma arquitetura existente, numa dada área ou região. Edificações, isoladamente ou em grupo, desde que consideradas representativas, são objeto de análise documentada e descrita em cartas-síntese. O levantamento se inicia no sítio, com fotos, desenhos, amostras de materiais (quando possível), e guias ou cartelas de cor. A observação metódica e analítica é o primeiro passo. A comparação dos resultados é feita entre cartas-síntese com as cores dos elementos principais da fachada, expressando a cor dominante ou o contraste. Visualmente correspondem a dados étnicos, sociais e culturais relativos à geografia da cor (LENCLOS, 2004).

Quando a amostra não pode ser obtida, as cores são identificadas com auxílio de peças de cores semelhantes e dos sistemas de notação, como o NCS (Natural Color System), Pantone Professional Color Selector ou RAL Design System. Quando a amostra pode ser feita manual e individualmente, isto é, uma a uma, utiliza-se o espectrocolorímetro e uma base eletrônica. A dificuldade em se obter ou reproduzir a tonalidade da amostra fabricada frente ao real, ao que está na edificação, é frequente (PORTER, 2009).

Tal mapeamento do existente, in loco, pode ser encaminhado com a tecnologia digital. Zena O'Connor descreveu um estudo de caso feito a partir de um edifício residencial em Berry`s Bay in Sydney. A metodologia parte da fotografia com alta resolução e do uso do Photoshop 7,0 para gerar arquivo tipo JPEG. A percepção visual foi recurso utilizado somente para a identificação das maiores áreas de cor, sendo a classificação da cor feita pelo sistema NCS (Natural Color System) no computador, reduzindo a vagueza da informação (Porter, 2009).

A análise visual configura-se também para Lois Swirnoff como um importante passo inicial. A localização geográfica deve ser enfatizada, já que a luz natural, derivada da relação geométrica do sol com a terra determina resultados que são apropriados culturalmente, tornando, por exemplo, mais eficazes relações de pouca luminosidade e cor em algumas regiões, e alta saturação e elevados ângulos de incidência solar, em outras áreas do globo (SWIRNOFF, 2000).

Esse artigo parte de pesquisa feita para elaboração de metodologia que auxilie na identificação e representação da imagem da cidade e de suas cores, sob luz natural. Tem como objetivo apresentar técnicas e métodos usados na representação gráfica de elementos da paisagem do Centro do Rio de Janeiro - área comercial conhecida por Saara, através de ensaios como a paleta de cores de fachada de edificação, figuras sínteses de mercadorias e transeuntes. Pretende-se contribuir para aperfeiçoamento da metodologia e de outras aplicações, acrescentando-se considerações sobre limitações inerentes ao processo. 
O Saara faz parte do Corredor Cultural (projeto do Governo Municipal), que busca a preservação, renovação e revitalização do patrimônio cultural (Instituto Municipal de Arte e Cultura - RJ, 2002). Há diretrizes para definição das cores dos elementos das fachadas dos imóveis preservados, e o contraste entre fachadas de edificações vizinhas é uma delas.

Instrumentos acessíveis ao estudante de arquitetura e ao arquiteto e urbanista, empregados regularmente no levantamento de informações sobre o contexto ambiental para o projeto, foram utilizados na pesquisa, sempre se confirmando o imprescindível respaldo da percepção visual, dada à complexidade do sistema. O roteiro metodológico seguiu os seguintes passos: I. visitas à área de estudo com registros preliminares; II. identificação de variações da iluminação natural no que diz respeito à trajetória solar e condições de nebulosidade; III. levantamento de aspectos históricos e culturais; IV. elaboração de dados primários fotografias e desenhos, in loco; V. elaboração de dados secundários e representativos - paletas de cores. VI. análise dos resultados.

Os resultados da pesquisa podem ser considerados como parte de um processo contínuo de revisão de técnicas gráficas e representação da paisagem a partir da percepção visual. Ao contrário do levantamento de cores da cidade, em que os pigmentos e técnicas de pintura são pesquisados em documentos (como nos estudos voltados ao patrimônio histórico), o levantamento do contexto urbano a partir da percepção visual é subjetivo, mas necessário. Destaca-se inclusive que, apesar de todo instrumental e aparato tecnológico disponível atualmente, a percepção visual é a balizadora de todo passo a passo do processo, desde a leitura do objeto visualizado à representação deste.

\section{2 ÁREA DE ESTUdO E ELEMENTOS EM DESTAQUE NA PAISAGEM}

A área de comércio popular de rua, no Centro do Rio de Janeiro, conhecida por Saara, possui uma história relevante, que acompanha a evolução da Cidade, com sobrados do início do século XX e uma ambiência reconhecidamente viva, que salta aos olhos e ouvidos.

Figura 1 - Quadras que compõem área de comércio chamada Saara

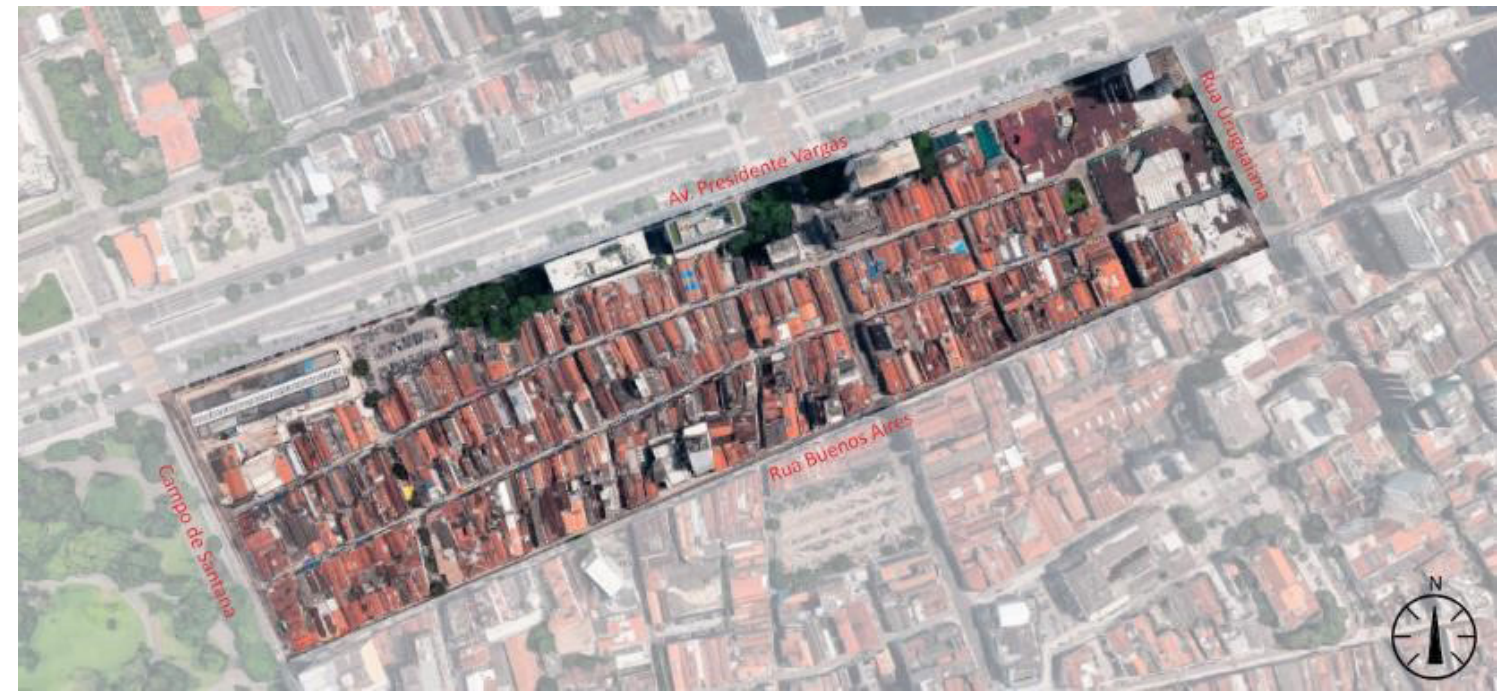

Fonte: Acervo dos autores com base do Google Maps acessado em 15/07/2016

Com edificações preservadas, as cores do lugar são contrastantes, sobretudo entre fachadas e entre elementos da fachada e toldos. As bancadas de mercadoria ficam dispostas não só no interior das lojas, mas avançam sobre o limite entre interior e calçada, entre o espaço privado e público, num convite à avaliação dos transeuntes, pelo toque, além da visão. A investigação do produto pelo comprador faz parte do ritual em compras no Saara. 
Há ruas exclusivas aos pedestres, que contribuem para o ritual de passagem, triagem e compra. Ruas estreitas, como a histórica Rua da Alfândega, em que o ângulo visual limita e induz a apreensão visual do lugar em tomadas pontuais. O número de frequentadores é significativo durante o dia, sobretudo, nos dias úteis. (Ver figs. 2 e 3)

Figura 2 - O Saara com sua diversidade

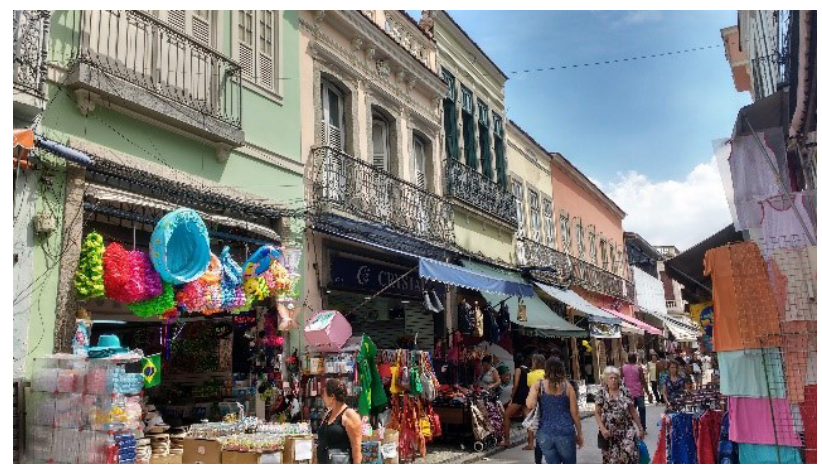

Fonte: Acervo dos Autores
Figura 3 - Sobrados na Rua da Alfândega

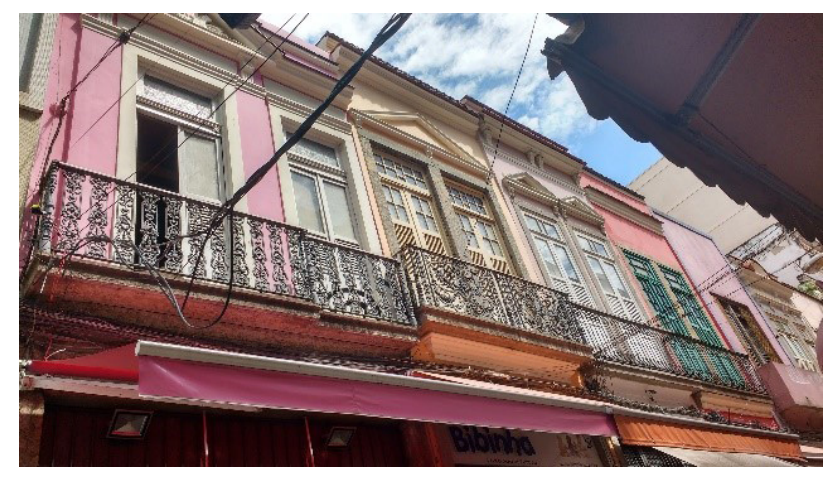

Fonte: Acervo dos Autores

Assim, após visitas para compreensão das características da ambiência do local, foram identificados elementos representativos, elaborados métodos e realizados ensaios para representação gráfica destes, que seriam: I. edificações vistas da rua, na altura do observador; Il. mercadorias expostas no limite entre loja e calçada; III. transeuntes das ruas de pedestres.

A diferenciação dos três grupos veio do reconhecimento de que cada um deles possui características que interferem na leitura e representação das cores. A começar pelas edificações, estruturas construídas, fixas, com volumetrias expostas à radiação solar, em planos distintos, sobretudo com orientações distintas. As fachadas geram contrastes, quando pintadas segundo critérios adotados pelo Corredor Cultural. Seja contraste entre sobrados e vizinhança, ou, numa mesma fachada do sobrado, entre parede, ornatos, esquadrias e toldos.

As mercadorias também constituem a paisagem da área do Saara, embora não sejam elementos fixos. Em alguns casos podem ser expostas, segundo uma organização que não só caracteriza a loja, mas que define padrões de textura e cor, quase indissociáveis. Ao contrário dos planos das edificações, as mercadorias têm dimensões reduzidas, formas infinitamente variadas, e estão, muitas vezes, agrupadas em cestas, cabides, ou seja, superpostas de modo diferente da tradicional vitrine. Entretanto, percebeu-se que a organização segue padrões de exposição que auxiliam na discriminação visual do comprador, sendo a cor um deles. O caráter provisório dos arranjos de mercadorias demandou diferentes métodos de representação gráfica daqueles adotados para as edificações.

Finalmente, as pessoas que circulam pelas ruas do Saara, que são determinantes na formação da ambiência e paisagem, de modo a compor um quadro que, por sua fluidez e não permanência, exigiram um método de representação distinto, seja das edificações, seja das mercadorias. Diante da variação evidente dos indivíduos, em que pese suas roupas, tons de pele, cabelo e adereços diversos, a representação buscou substituir o individual pelo coletivo, o específico pelo abrangente.

\section{MÉTOdOS E ENSAIOS}

Ao longo da pesquisa, confirmou-se a importância da percepção visual, entendendo-a como o recurso que estabelece o quadro visual real e, portanto, balizador da avaliação da pertinência dos métodos de representação e de seus resultados. O objeto percebido em sua aparência, conta com a presença da luz (no caso, natural), com a estrutura molecular da matéria que a reflete seletivamente, e com a visão humana. É subjetivo, mas constitui a referência do real. Diferentemente de dizer que a cor é propriedade objetiva de um objeto físico, sustentamos que a percepção da cor vem da experiência da observação, sob condições de luminosidade variáveis, influenciada pela materialidade do observado (MAUND, 2009). 
A associação entre visão e realidade concebida pode ser ilustrada por trecho destacado de reflexões de Marilena Chauí, referente ao olhar: "Cremos que as coisas e os outros existem porque os vemos e que os vemos porque existem. (...) Porque cremos que a visão se faz em nós pelo fora e, simultaneamente, se faz de nós para fora, olhar é ao mesmo tempo, sair de si e trazer o mundo para dentro de si" (MARILENA CHUAI in NOVAES, 2003, p.33).

Assim, a imagem vista na cidade é de natureza distinta de sua representação análoga - a fotografia; que por sua vez, é sintetizada num outro análogo, dessa vez, de natureza semelhante - a paleta de cores. A imagem da fotografia e da paleta testemunharia o existente, externo ao observador, seja para ser usada numa narrativa à distância, seja para simplificação do objeto real - a simplificação da paisagem para avaliação específica - o contexto arquitetônico, urbano e cultural.

A avaliação pelo sentido da visão perpassa todo o processo metodológico experimentado e elaborado, embora não seja absolutamente um instrumento exclusivo.

A mídia eletrônica vem complementando o papel como suporte de imagens representadas. A fotografia e análise de suas cores servem ao propósito de registros dessa natureza. Assim, como recursos de apoio, destacaram-se: a câmera fotográfica geradora de fotos em formato jpeg (ainda que o formato raw fosse mais interessante, foi evitado dado não ser o usual no momento), independente ou interna ao aparelho de telefone móvel (celular), o computador para visualização, interferência, e síntese das imagens, softwares gráficos (com destaque para o AdobePHOTOSHOP, da Abobe, e o CorelDRAW, da Corel Corporation), desenho de observação elaborado in loco, em papel, e uma cartela de cores referencial, em papel, da DGK Color, de 18 cores (ver figura 16).

Como condicionante, adotou-se recursos acessíveis a estudantes e arquitetos em atividades dessa natureza. A ideia central era criar um método ajustado ao ferramental disponível atualmente, gerando formulações com um bom grau de correlação entre o existente e o representado.

As formas de representação são aqui exemplificadas:

i. Edifícios e paleta - para representação do edifício, optou-se pela construção de células, como campos homogêneos de cor, uma unidade de tamanho visualmente coerente com a parte da fachada estudada. Um conjunto de células (delimitado individualmente em quadrados ou associadas em círculo) gerou o que chamamos de paleta de cores (Ver figs. 4, 5 e 6).

Figura 4 - Divisão dos campos de cor por luminosidade
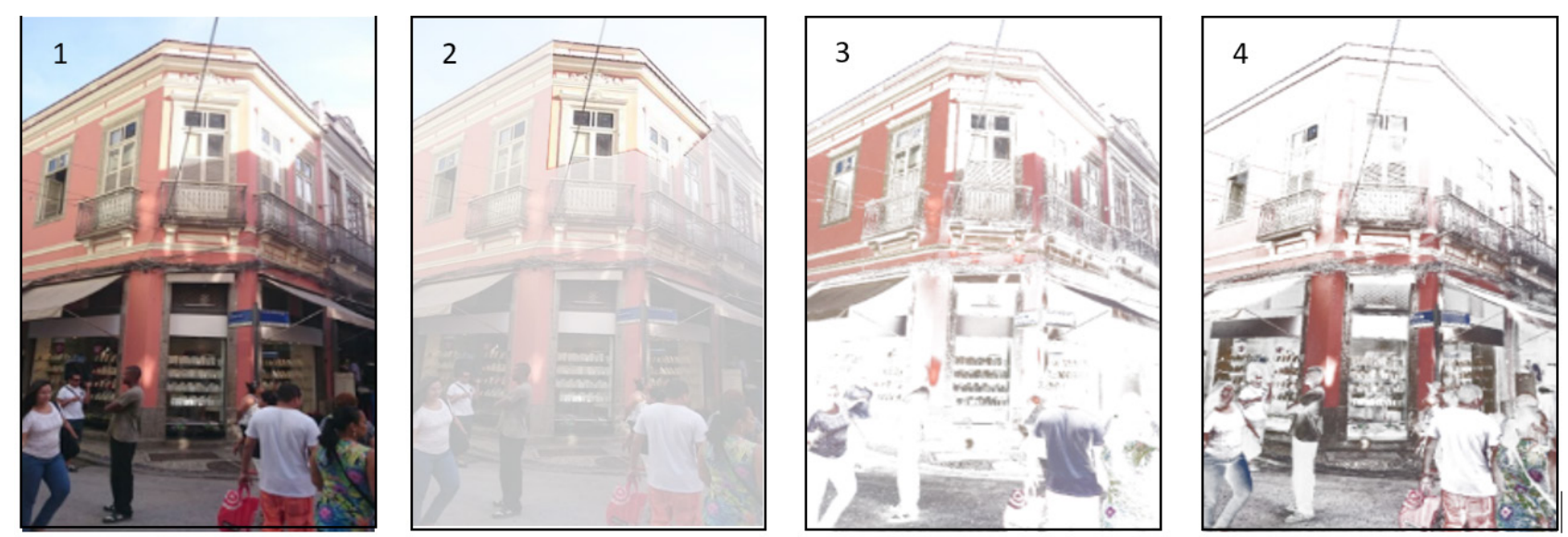

1 - Edifício considerado para a análise (esquina R. da Alfândega com R. Reg. Feijó); 2 -Campo de cor 01 (com maior luminosidade); 3 - Campo de cor 02 (com luminosidade média); 4 - Campo de cor 03 (com menor luminosidade). Fonte: Acervo dos autores 
Figura 5 - Seleção de células

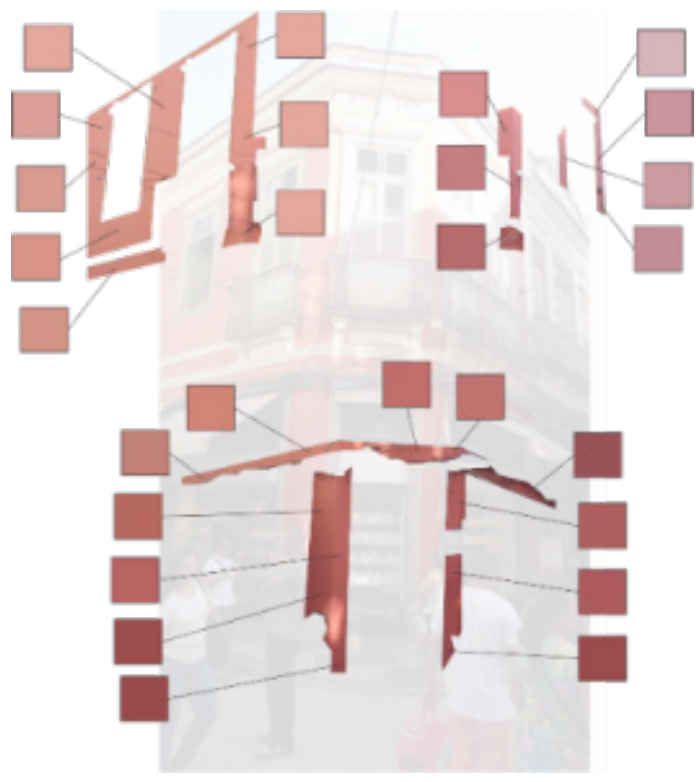

Fonte: Acervo dos autores

Figura 6 - Organização de paletas

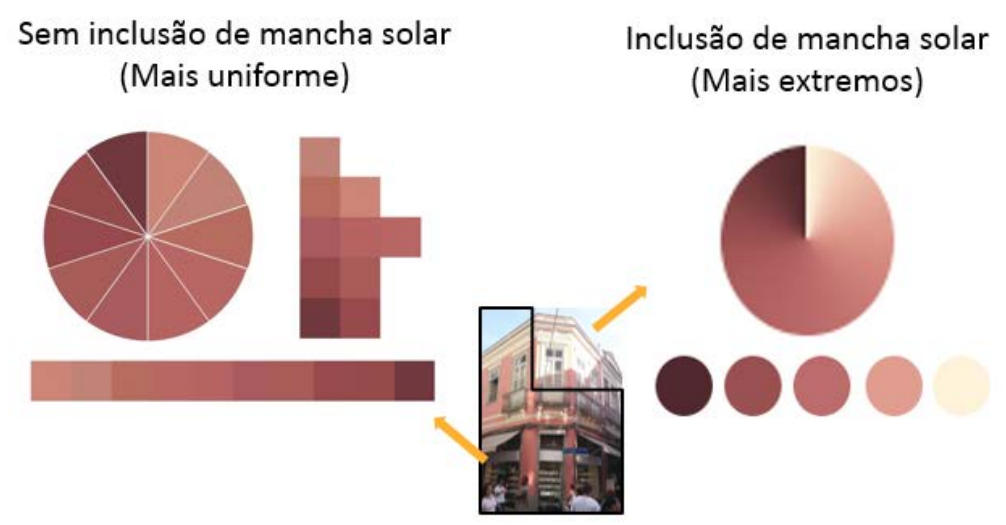

Fonte: Acervo dos autores

ii. Mercadorias e células - para representação das mercadorias, optou-se pela elaboração de células, através de recortes seletivos diretamente das fotos. Assim, a célula retangular ou quadrada, de tamanho compatível com a representatividade em questão, compunha uma paleta, em que a textura foi também indiretamente apresentada como elemento análogo ao real (Ver fig.7).

Figura 7 - Mercadoria e suas respectivas células

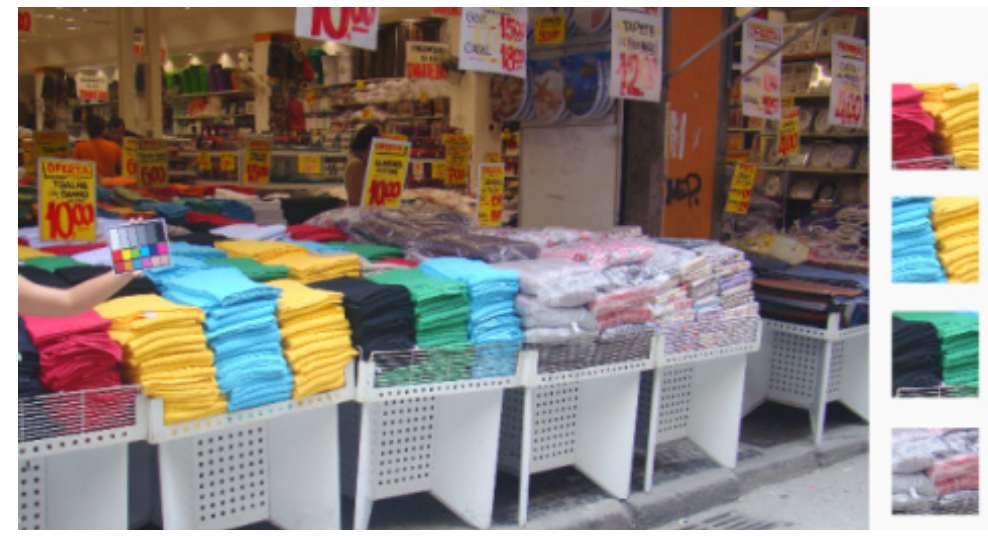

Fonte: Acervo dos autores 
iii. Pessoas - para representação das pessoas, a célula deu lugar a uma imagem onde buscou-se representar o movimento e a diversidade das pessoas, o que não foi possível com um único registro. Foram feitas várias imagens de um ponto de vista, buscando a proximidade de uma expressão desse movimento. Nos ensaios, adotou-se um formato que permitiu a representação das imagens em sequência - formato GIF. No caso de uma figura estática (como apresentada a seguir) foi atribuído um valor de transparência para cada imagem, as quais foram sobrepostas, de modo a simular a animação. (Ver fig. 8,9 e 10)

\section{Figura 8 - Pessoas desfocadas e destacadas do fundo}

1

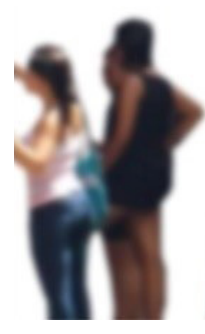

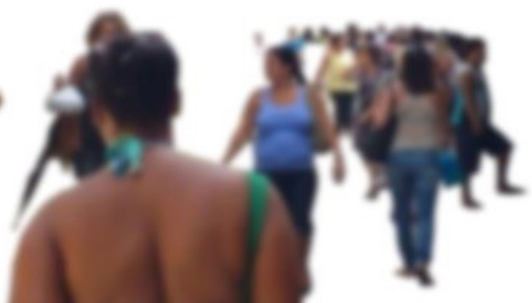

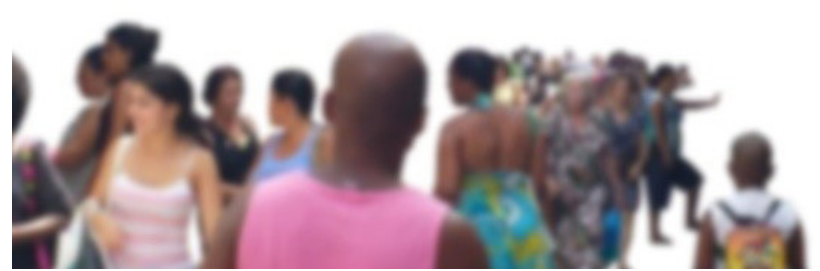

2
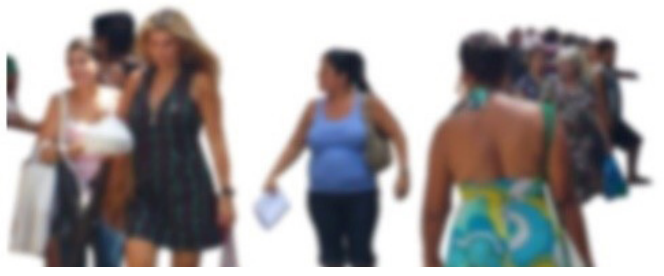

4

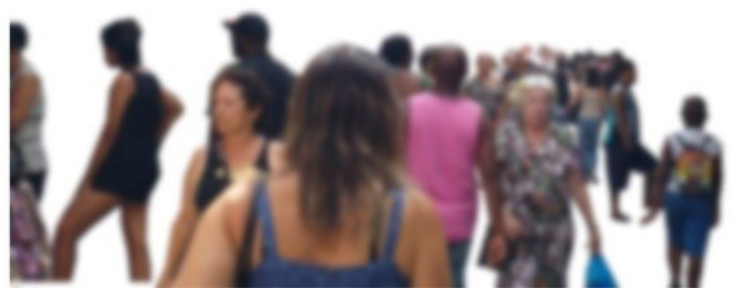

Sequência de imagens (1 - 4) a partir de um mesmo ponto de vista, buscando a expressão do movimento das pessoas. Fonte: Acervo dos Autores

Figura 9 - Sobreposição das imagens 1 - 4 sem o fundo Figura 10 - Sobreposição das imagens 1 - 4 com o fundo

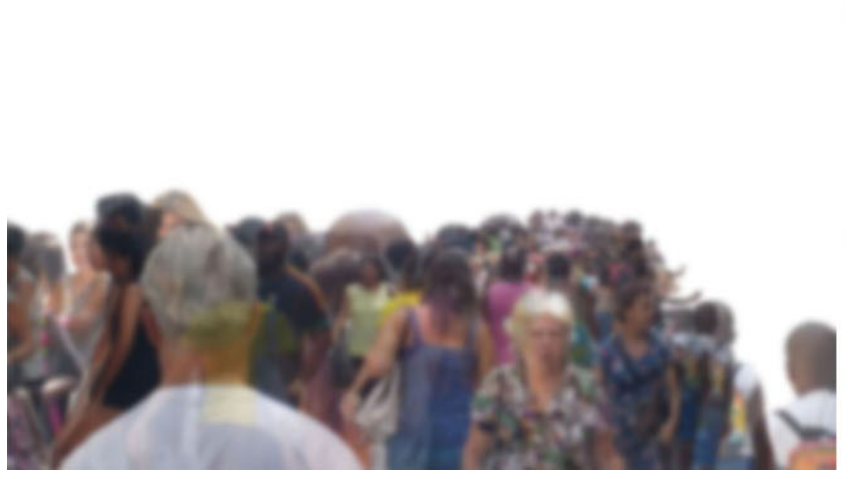

Fonte: Acervo dos autores

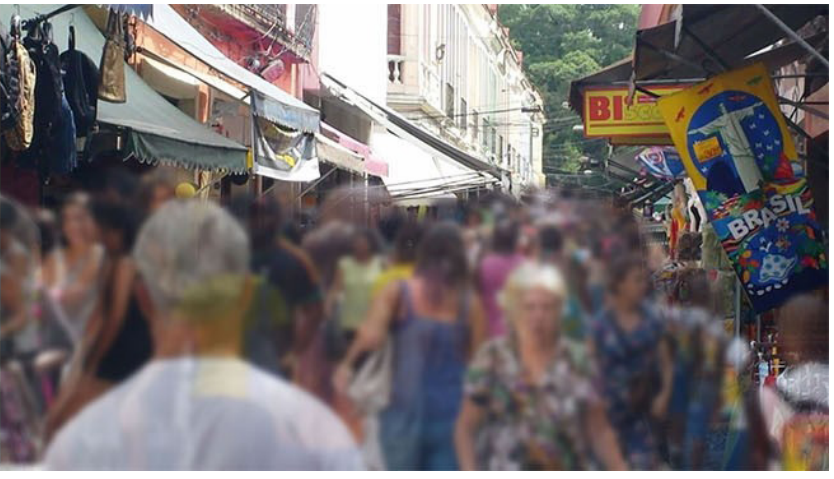

Fonte: Acervo dos autores

\section{ALGUNS DESTAQUES RELATIVOS A RECURSOS E INSTRUMENTOS}

O que caracteriza a imagem urbana é, sem dúvida, a quantidade de elementos presentes, suas complexas interações e contínuas variações. Além disso, se a cor é percebida pelos olhos frente à luz que incide, e a própria luz variável, o resultado da visão e da representação do visualizado tem um caráter de imprecisão elevado.

Desse modo, durante a sequência de passos para o ensaio realizado, alguns recursos foram criados para contribuir para a melhoria da qualidade da representação da imagem. Dentre esses, destaca-se a seguir:

\section{i. O desenho em preto e branco da fachada contribuindo para uma isenção do olhar;}


Tendo sido selecionada a edificação cujas cores seriam sintetizadas numa paleta, propôs-se fazer um desenho em preto e branco, do ângulo observado, para discriminação e delimitação do elemento estudado. O reconhecimento de que os campos de cor visualizados constituem informações mais do que relevantes, autosuficientes, teve como contrapartida, na metodologia elaborada, sua momentânea retirada de cena em desenhos p \& b. A intenção é racionalizar o processo da percepção visual (Ver fig. 11).

Figura 11 - Destaque de elementos através do desenho
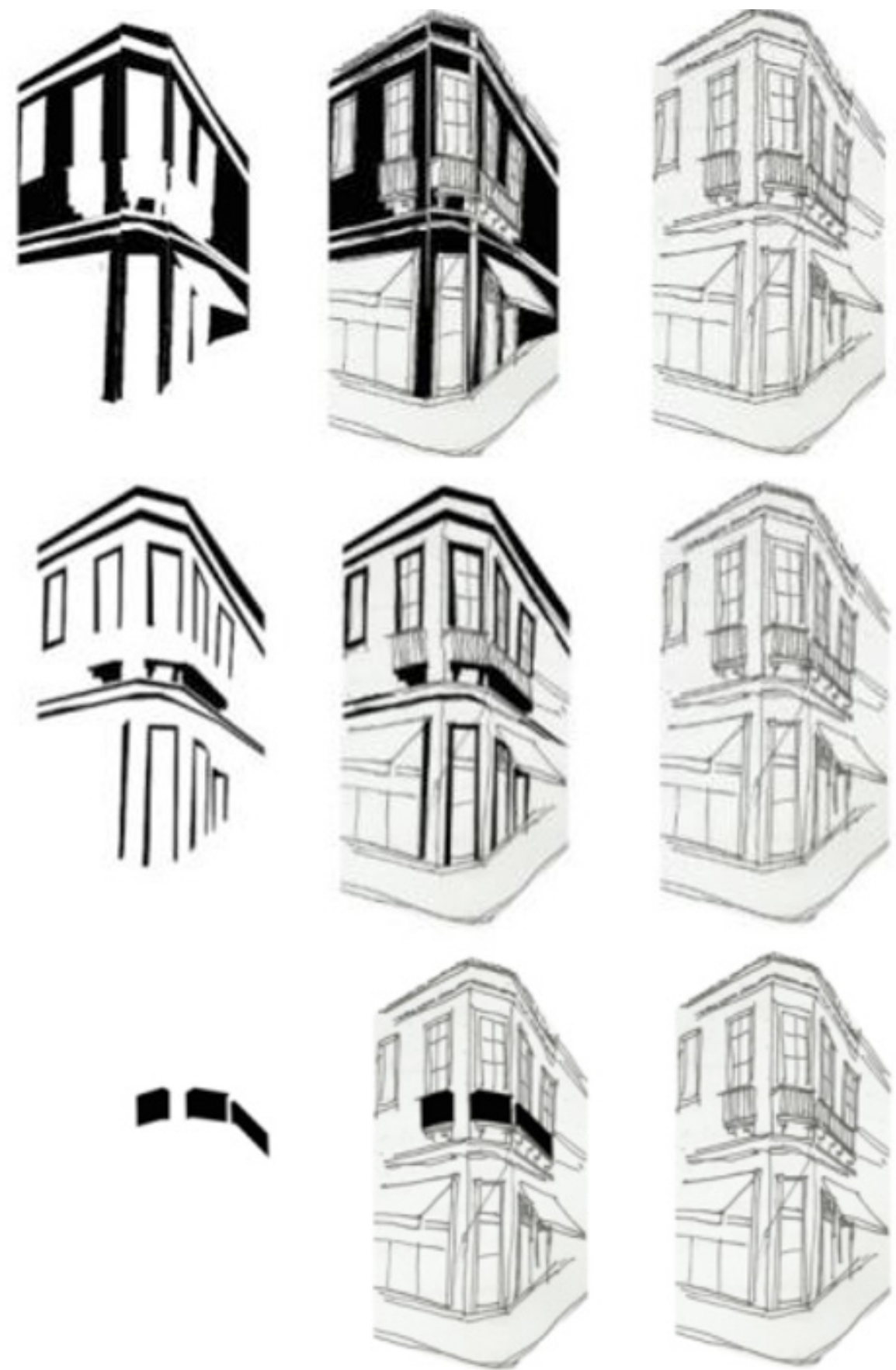

Fonte: Acervo dos autores

\section{ii. A maquete como recurso para identificação de variações da luz do sol sobre a cena estudada}

A qualidade da luz natural varia em função da trajetória solar e composição atmosférica. A percepção da cor depende ainda da incidência da luz na volumetria e superfície visualizada. A maquete com edificações e vias permite a simulação da incidência da luz do sol, correspondente a dias de céu claro. (Ver figs. 12 e 13) 
Figura 12 - Maquete eletrônica do Saara - Inverno - 8h da manhã

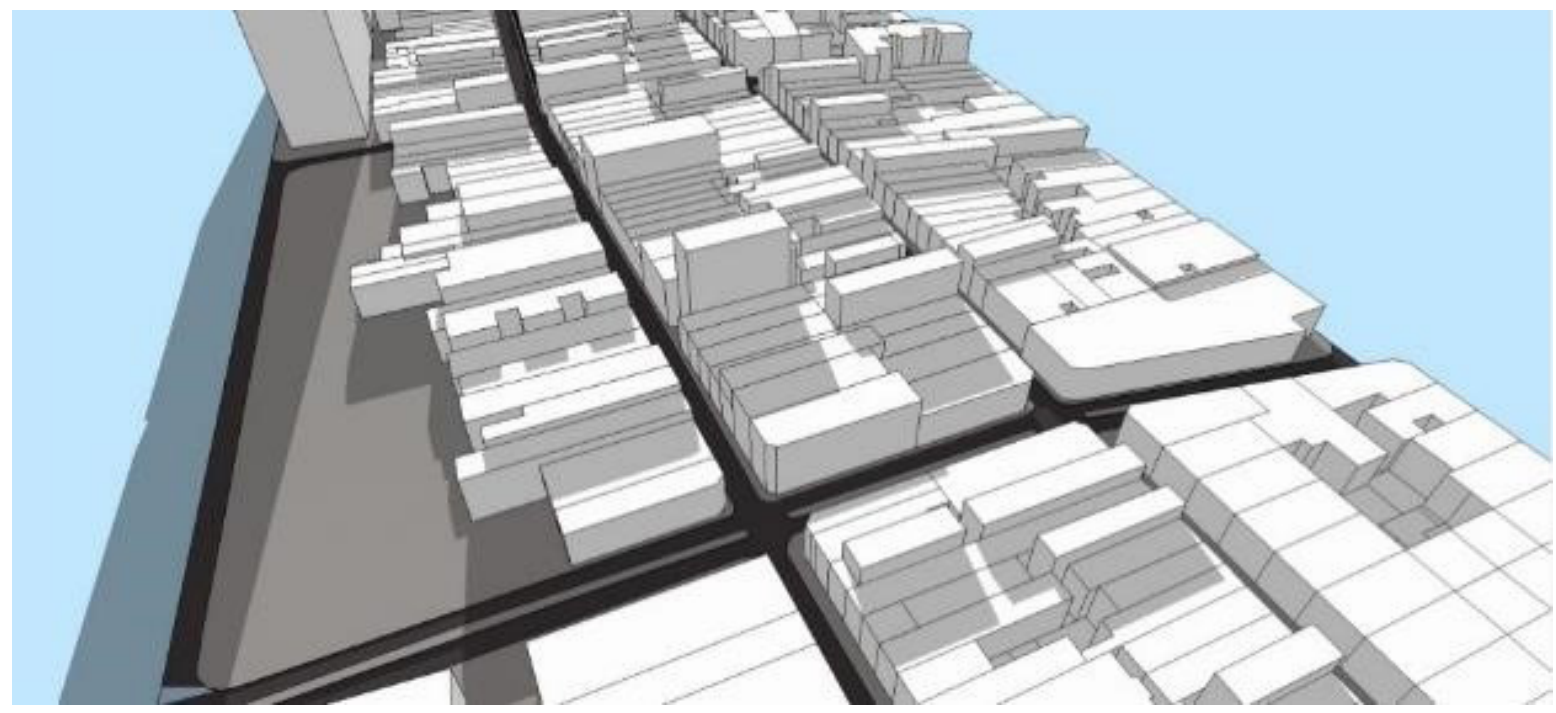

Fonte: Acervo dos autores

Figura 13 - Conjunto de imagens exemplificando a diferença de percepção do mesmo local, às 9h, 12h e 15 h, respectivamente, em função da incidência solar.
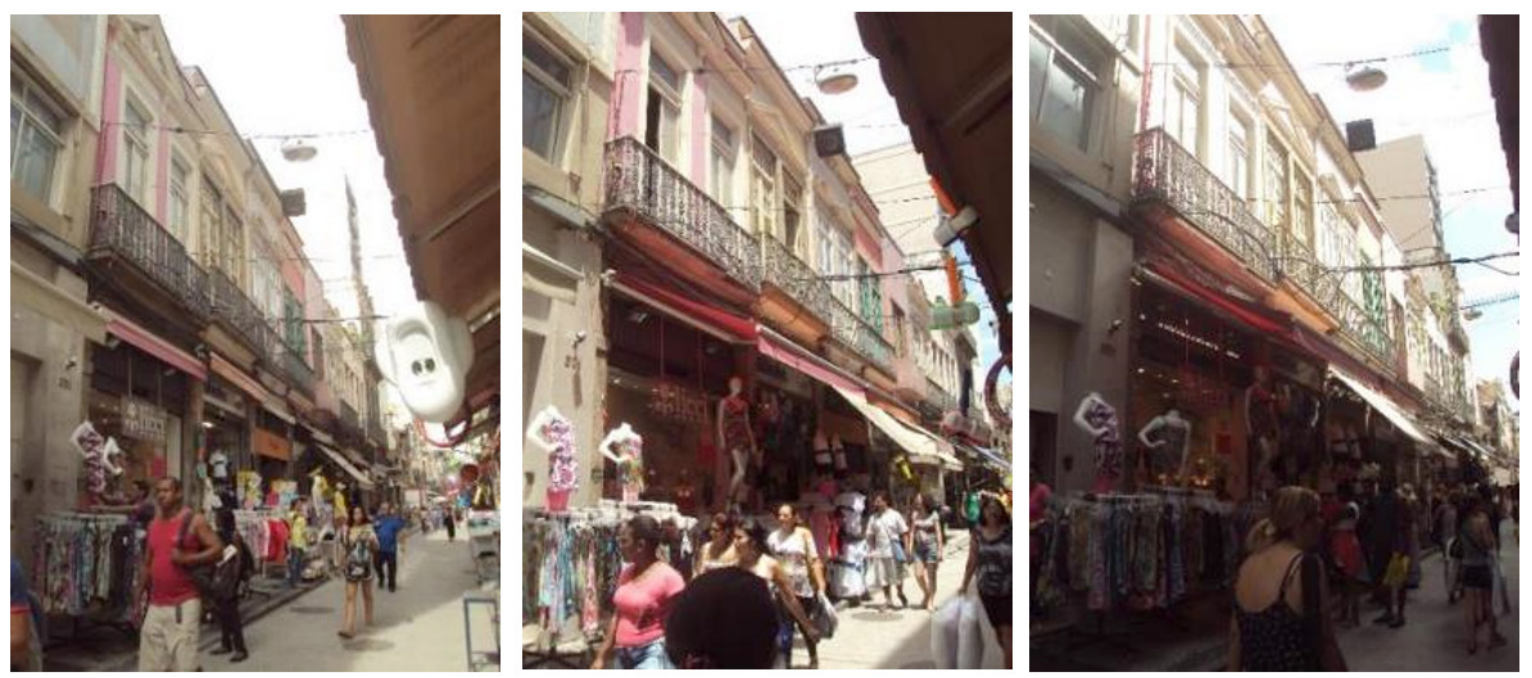

Fonte: Acervo dos autores

\section{iii. O registro das condições de nebulosidade}

O ambiente sob céu claro ou parcialmente encoberto (ambos com a presença da luz do sol) contém mais contrastes de cor. Assim, há que se agrupar e analisar os registros (imagens) primários (fotografias) segundo esse critério.

\section{iv. Os campos de cor na figura do edifício sob sol e sombra}

Um mesmo plano de um objeto tridimensional tem campos de cor diferenciados por contrastes de brilho e cor. O reconhecimento dessas áreas foi feito, com auxílio do software e da percepção visual. (Ver fig.14) 
Figura 14 - Destaque dos diferentes campos de cor do edifício
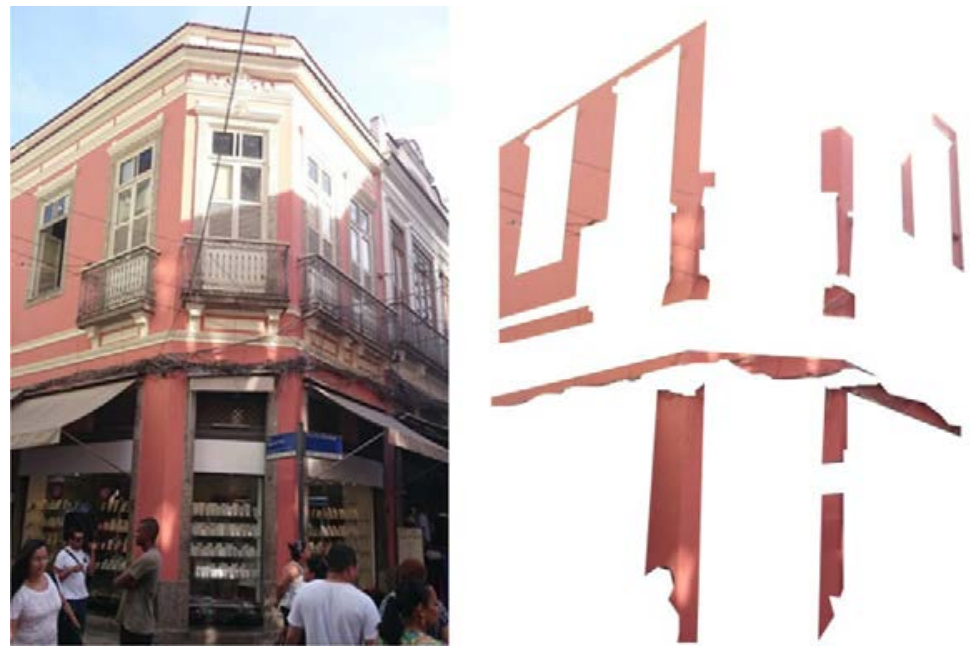

Fonte: Acervo dos autores

\section{v. A restrição ao zoom na imagem virtual}

A síntese das cores, em células e paleta, exige cuidado no que diz respeito ao uso do zoom, como ferramenta computacional de aproximação da distância de visualização. A percepção visual determina o que é considerado real, e o aumento da imagem, sua formação em pixels, pode não corresponder ao visualizado.

\section{vi. A validação das células, com a superposição na fotografia}

Um recurso interessante utilizado e recomendado é a superposição das células na foto original - dado primário, para validação da escolha para formação da paleta. A percepção visual gera o julgamento (Ver fig. 15).

Figura 15 - Seleção de Células e sobreposição destas sobre a imagem original
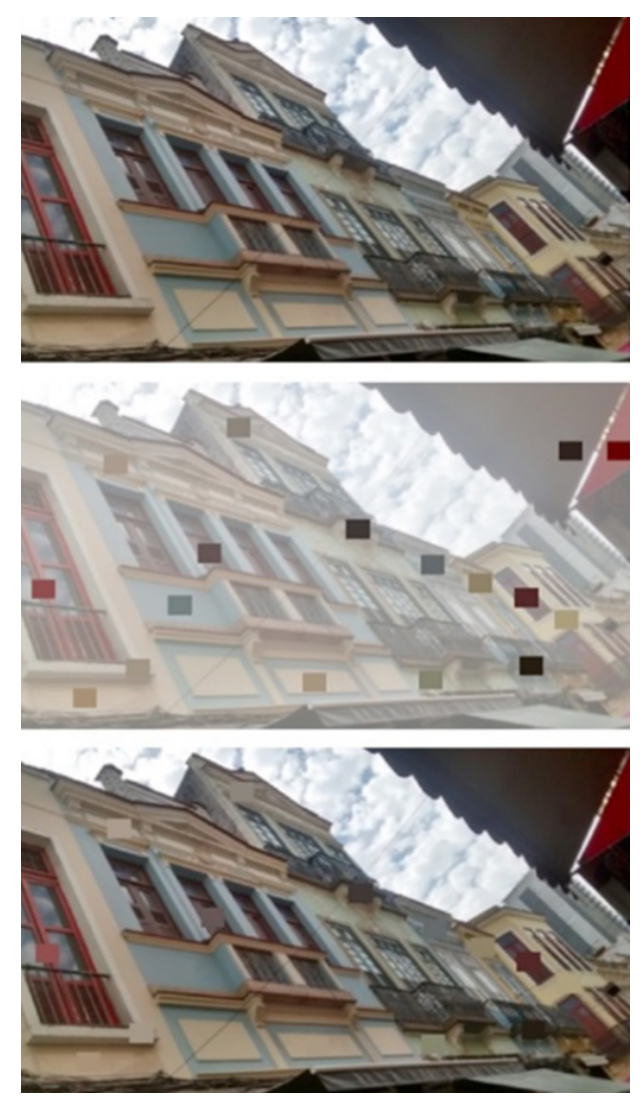

Fonte: Acervo dos autores 


\section{vii. O uso da carta de cores e ajustes da imagem}

A cartela de cores (Ver fig. 16) como instrumento para os registros das edificações não se mostrou nada adequada, seja por conta da distância visualizada, da escala do objeto ou exposição à luz heterogênea. No registro das mercadorias, o ensaio pôde ser realizado, embora a qualidade resultante não tenha sido suficiente para estabelecer uma rotina.

Figura 16 - Cartela de cores digitalizada

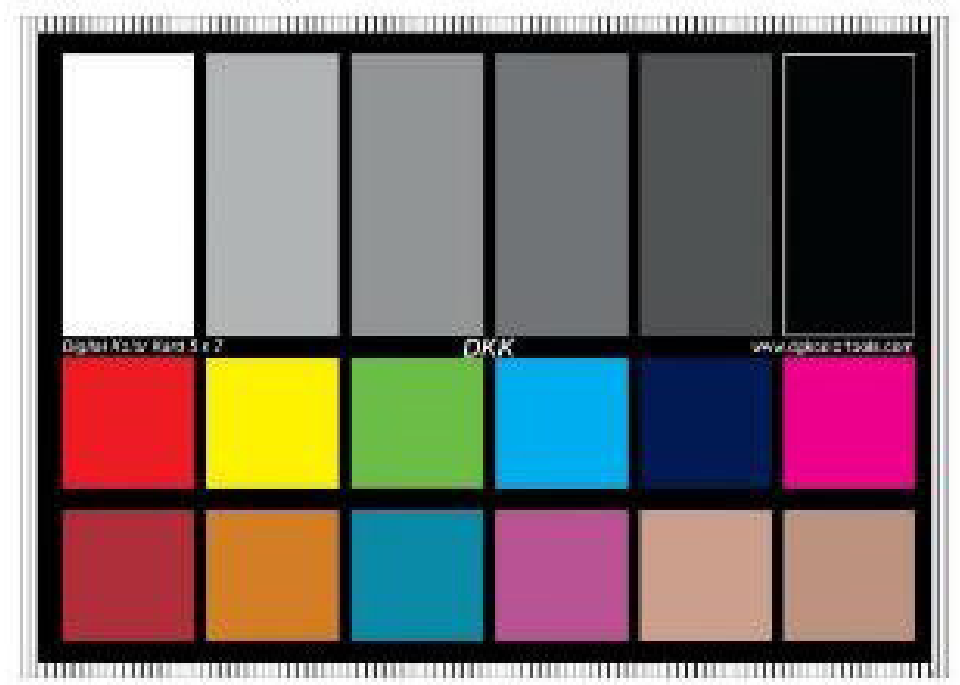

Fonte: Acervo dos autores

Ilustra-se o potencial e a limitação da cartela na leitura das mercadorias sob dois tipos principais de iluminação - a natural no exterior e a artificial no interior da loja.

Vale destacar que, de uma forma geral, os valores RGB da imagem da cartela em fotos não correspondem às cores da cartela impressa - discriminados em seu rodapé. Por exemplo, nesse caso, podem ser comparados os valores RGB do vermelho, que na foto são $R=244 ; G=64 ; B=72$ e na cartela impressa são $R=235 ; G=28$; $B=36 .($ Ver fig. 16 e 17)

Figura 17 - Foto não manipulada com a cartela de cor (em destaque)

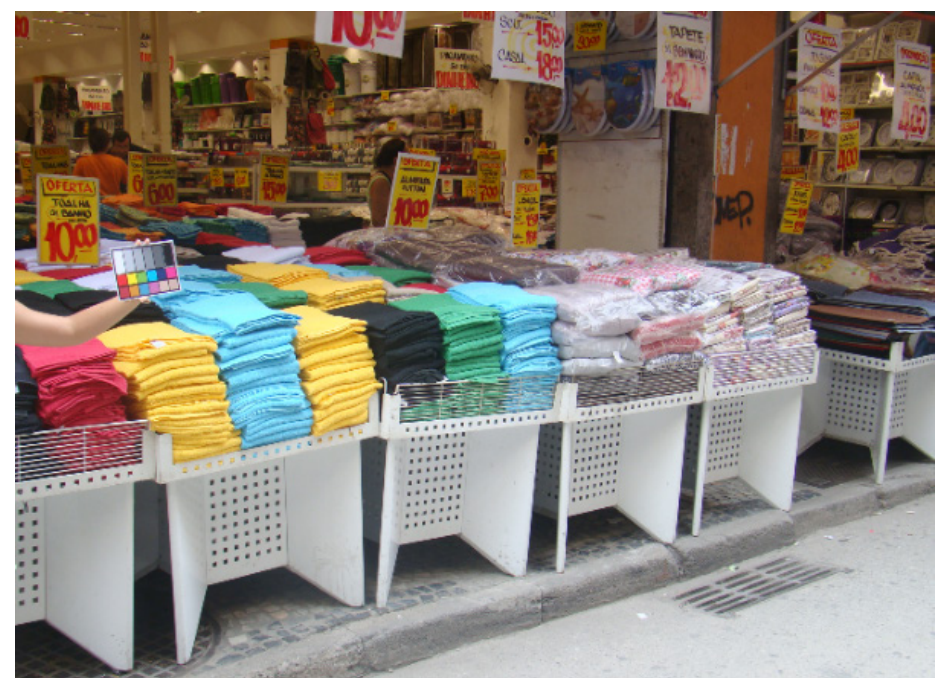

Fonte: Acervo dos autores 
Foi constatado um desvio da proposta original da pesquisa com o uso da cartela para correção, visto que a cartela tem como objetivo a possibilidade de reprodução fidedigna das cores de objetos no meio fotográfico. Isso significa desconsiderar as influências externas do ambiente e se mostra problemático especialmente em ambientes com diversos tipos de iluminação, como na fotografia analisada. A cartela se mostra um instrumento útil quando o se busca uma reprodução de elementos em ambientes uniformes e com uma luz padrão, mas se mostra pouco útil à pesquisa que deseja a caracterização de um ambiente diverso, com variações de iluminação.

Assim, esses sete itens listados acima traduzem aspectos da complexidade do processo, dos potenciais e limites dos recursos destacados nos ensaios - elaboração de paletas de cores de fachada, mercadorias e transeuntes da área estudada, que pode em maior ou menor grau servir de referência para levantamentos de cores da paisagem urbana.

\section{CONSIDERAÇÕES FINAIS}

Alguns trabalhos versam sobre elementos da paisagem, suas cores e a identidade cultural. Por vezes, tratam do patrimônio e cor, e quando assim o fazem, se apoiam na especificação de pigmentos usados. Outros referemse à paisagem a partir da apreensão visual. A questão é que se cor e luz são indissociáveis e a luz natural variável, gerar registros gráficos dessa natureza deve levar em conta a variação da aparência das coisas. E para se ter qualidade gráfica, ou seja, obter algum grau de fidelidade na apresentação da cena, os métodos devem seguir uma sequência de passos, ajustada aos objetivos, particularidades da cena e recursos disponíveis.

No artigo foi destacada a natureza, e ilustrada a forma de representação de cores correspondentes à fachada de uma dada edificação, algumas mercadorias e pessoas, segundo elaborado pelo grupo de pesquisa. Elementos distintos demandaram soluções distintas. A falta de sentido na representação das pessoas em células individuais extrapolou a formatação inicial da paleta e da figura estática, por exemplo.

A cada ensaio, empírica e intuitivamente, os métodos eram ajustados. A tecnologia se revelou como auxiliar indispensável, mas sempre balizada pela percepção visual. Se cada resultado parcial obtido não era satisfatório frente ao julgamento feito visualmente, o modo de proceder era alterado ou descartado, como no caso do uso da ferramenta de zoom dos softwares gráficos.

Considerou-se que cada caso - recorte urbano, cena, local de observação, condições de luz natural, entre outras variáveis, demanda adequação dos métodos, não havendo, portanto, uma metodologia universal, nem mesmo abrangente. Cada estudo elaborado e descrito constituirá uma referência para novos trabalhos com intenção semelhante. Se a paisagem é patrimônio cultural, reunindo elementos infinitos, sua importância e aplicações acadêmicas e profissionais serão sempre necessárias, embora desafiadoras.

Finalmente há que se considerar o avanço acelerado de novas tecnologias no campo da reprodução e representação de imagens, o que auxiliará na precisão do processo, também em arquitetura.

\section{REFERÊNCIAS}

INSTITUTO MUNICIPAL DE ARTE E CULTURA (RJ), Corredor Cultural: Como reformar ou construir seu imóvel, Rio de Janeiro: RIO ARTE, IPP, 2002. LENCLOS, Jean Philippe; LENCLOS, Dominique. Colors of the World - The geography of color. New York: W.W. Norton \& Company, 2004. NOVAES, Adauto. (org.) O Olhar. São Paulo:Companhia das Letras, 2003.

MAUND, Barry. Colours - Their nature and representation. Cambridge: Cambridge University Press, 2009.

PORTER, TOM, MIKELLIDES, Byron, Colour for ArchitectureToday. London: Taylor and Francis: 2009.

RIOARTE, A Cor-Corredor Cultural. Coleção Corredor Cultural, vol. 1, Rio de Janeiro: Imprinta Gráfica e editora, 1990.

SWIRNOFF, Lois. Colors of Cities - An International Perspective, NY: Mc Graw Hill, 2000.

NOTA DO EDITOR (*) O conteúdo do artigo e as imagens nele publicadas são de responsabilidade do(s) autor(es). 